\title{
Ultrasonic doppler flowmeter-guided occipital nerve block
}

\author{
Se Hee $\mathrm{Na}^{1,2}$, Tae Wan $\mathrm{Kim}^{3}$, Se-Young $\mathrm{Oh}^{1}$, Tae Dong Kweon ${ }^{1,2}$, Kyung Bong Yoon ${ }^{1,2}$, and Duck Mi Yoon ${ }^{1,2}$ \\ ${ }^{1}$ Department of Anesthesiology and Pain Medicine, ${ }^{2}$ Anesthesia and Pain Research Institute, Yonsei University College of Medicine, \\ Seoul, ${ }^{3}$ Department of Anesthesiology and Pain Medicine, CHA University School of Medicine, Pocheon, Korea
}

Background: Greater occipital nerve block is used in the treatment of headaches and neuralgia in the occipital area. We evaluated the efficacy of ultrasonic doppler flowmeter-guided occipital nerve block in patients experiencing headache in the occipital region in a randomized, prospective, placebo-controlled study.

Methods: Twenty-six patients, aged 18 to 70, with headache in the occipital region, were included in the study. Patients received a greater occipital nerve block performed either under ultrasonic doppler flowmeter guidance using $1 \%$ lidocaine or the traditional method. Sensory examination findings in the occipital region were evaluated.

Results: The complete block rate of greater occipital nerve blockade in the doppler group was significantly higher than in the control group respectively $(76.9 \%$ vs. $30.8 \%, \mathrm{P}<0.05)$. Only one patient in the control group had a complication (minimal bleeding).

Conclusions: Ultrasonic doppler flowmeter-guided occipital nerve block may be a useful method for patients suffering headache in the occipital region. (Korean J Anesthesiol 2010; 59: 394-397)

Key Words: Doppler ultrasonography, Migraine disorders, Neuralgia, Occipital nerve, Post-traumatic headache.

\section{Introduction}

Greater occipital nerve block (GONB) is performed either to diagnose or treat pain in the occipital area [1], and is an effective treatment for migraines and cervicogenic, cluster, and postdural puncture headaches $[2,3]$.

Two different injection techniques are used to perform occipital nerve blocks. One is the proximal injection technique: anesthetic is injected into the muscle at the point of greater occipital nerve (GON) exit. As a result, the paraspinal muscles near the injection site are also infiltrated with anesthetic, coming to paraspinal muscle injection that may well be a trigger point injection [4]. The other technique (traditional technique) is administered more distally: GONB is performed just medial to the occipital artery, which is palpated at $2.5-3 \mathrm{~cm}$ lateral to the occipital protuberance [5-7]. Identification of the greater occipital artery is important in performing a successful occipital nerve block, when the latter method is used. However, finding the pulse of the greater occipital artery may not be possible because of its size, the course is variable, and hair often covers it [8].

We hypothesized that ultrasonic doppler flowmeter would be useful when GONB is performed using the traditional

Received: January 15, 2010. Revised: 1st, February 16, 2010; 2nd, April 16, 2010. Accepted: July 21, 2010.

Corresponding author: Duck Mi Yoon, M.D., Department of Anesthesiology and Pain Medicine, Yonsei University College of Medicine, 134, Sinchon-dong, Seodaemun-gu, Seoul 120-752, Korea. Tel: 82-2-2228-2420, Fax: 82-2-312-7185, E-mail: dmyoon@yuhs.ac

(c) This is an open-access article distributed under the terms of the Creative Commons Attribution Non-Commercial License (http:// creativecommons.org/licenses/by-nc/3.0/), which permits unrestricted non-commercial use, distribution, and reproduction in any medium, provided the original work is properly cited. 
technique. The aim of this study was to evaluate the efficacy of ultrasonic doppler flowmeter-guided greater occipital nerve blocks.

\section{Materials and Methods}

Following Institutional Review Board approval, informed consent was obtained from patients (age range, 18-70 years) diagnosed with occipital neuralgia and cervicogenic headache. Diagnosis of occipital neuralgia and cervicogenic headache was defined based on the International Headache Society classification [9].

Exclusion criteria were: a known history of allergic reaction to local anesthesia; coagulopathies; clinically relevant abnormalities; headache receiving concurrent psychiatric therapy; organic disease of the brain or spinal cord; cancer.

Patients were then randomly divided into two equal groups of 13 patients, the traditional method (Group C) and the ultrasonic doppler flowmeter-guided method (Group D).

Group C technique: In the prone position, the superior nuchal line was defined from the mastoid to the cervical spine at C1-2. Following palpitation of the occipital artery pulse above the superior nuchal line about 2.5 to $3 \mathrm{~cm}$ lateral to occipital protuberance and aseptic preparation of the skin, $1 \%$ lidocaine $3 \mathrm{ml}$ was infiltrated using a $27-\mathrm{G}$ needle, just medial to the occipital artery. Group D technique: In the prone position, an ultrasonic doppler flowmeter (Summit Doppler, Listening to Life $^{\mathrm{TM}}$, Colorado, USA) probe was moved horizontally along the superior nuchal line until occipital artery flow became audible. After the probe was manipulated back and forth until the most audible site was found, $1 \%$ lidocaine $3 \mathrm{ml}$ was injected just medial to this site (Fig. 1). All blocks were performed by the

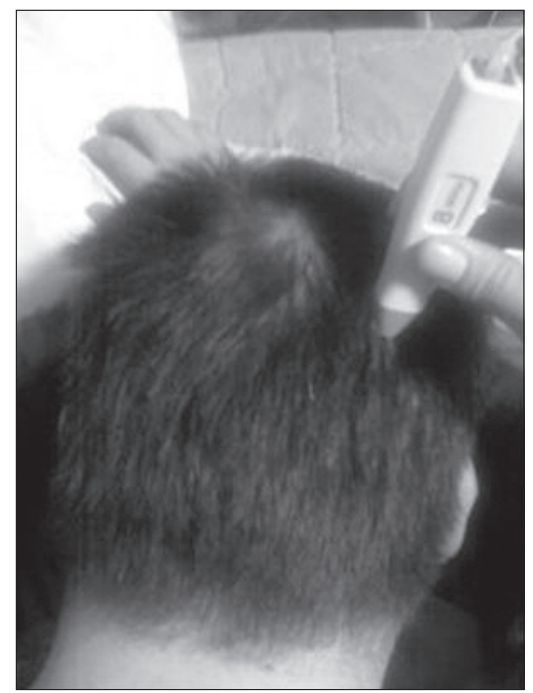

Fig. 1. Occipital artery can be detected by ultrasonic doppler flowmeter. same anesthesiologist.

Demographic data including age, gender, weight, and height were recorded in addition to the distance between occipital protuberance and injection site. Sensory loss to pinprick was assessed and compared to the contralateral area using a pinprick test, performed 5 minutes after injection, and pain reduction was checked after 15 minutes. Sensory block and pain reduction were recorded using a numeric rating scale (NRS, 0 representing complete absence of sensation and pain; 10 as no difference). The degree of sensory loss was classified as complete (NRS of sensation $=0$ ), partial $(1-9)$, or none (10). Post-block complications such as dizziness, subcutaneous hematoma, bleeding, and arterial puncture were recorded, as well.

In our pilot study, the success rate of complete blockade was $37.5 \%$ in the Group C (3/8) and 90\% (9/10) in the Group D. A sample size of 13 patients for each group was needed to achieve a significance level of $5 \%$ and a power of $80 \%$. SPSS (version 15.0, SPSS Inc., Chicago, IL, USA) - specifically, chi-square, t-test, and Mann-Whitney test - was used in between-group comparisons of sensory block and pain reduction scores. A P value $<0.05$ was considered statistically significant.

\section{Results}

Twenty-six patients were included in the analysis. The two groups had similar baseline demographic characteristics (Table 1). Success rate of complete GONB was significantly higher in Group D than Group C (Table 2). Distance between occipital protuberance and injection site, and pain reduction scores did not significantly differ between the two groups (Table 2).

One postblock complication (minimal bleeding at injection site) in Group C was noted.

\section{Discussion}

This study investigated the efficacy of Ultrasonic doppler flowmeter-guided GONB, and we believe this is the first time

Table 1. Demographic Data

\begin{tabular}{lcc}
\hline & Group C $(\mathrm{n}=13)$ & Group D $(\mathrm{n}=13)$ \\
\hline Age $(\mathrm{yr})$ & $53.8 \pm 11.3$ & $55.7 \pm 10.6$ \\
Gender $(\mathrm{M} / \mathrm{F})$ & $6 / 7$ & $8 / 5$ \\
Weight $(\mathrm{kg})$ & $62.2 \pm 13.7$ & $65.0 \pm 13.4$ \\
Height $\left(\mathrm{cm}^{2}\right)$ & $160.7 \pm 11.0$ & $162.8 \pm 9.3$ \\
Pain site $(\mathrm{Rt} / \mathrm{Lt})$ & $5 / 8$ & $6 / 7$ \\
\hline
\end{tabular}

Values are mean \pm SD except gender and pain site. There were no significant differences between groups. Group C: conventional greater occipital nerve block group, Group D: ultrasonic doppler flowmeter-guided greater occipital nerve block group, M: male, F: female. 
Table 2. Success Rate of Injections

\begin{tabular}{|c|c|c|}
\hline & Group C $(n=13)$ & Group D $(\mathrm{n}=13)$ \\
\hline Distance $^{*}(\mathrm{~cm})$ & $3.5 \pm 0.5$ & $3.8 \pm 0.8$ \\
\hline \multicolumn{3}{|l|}{ Sensory change } \\
\hline None & 0 & 0 \\
\hline Partial & $9(69.2 \%)^{\dagger}$ & $3(23.1 \%)^{\dagger}$ \\
\hline Complete & $4(30.8 \%)^{\dagger}$ & $10(76.9 \%)^{\dagger}$ \\
\hline Pain (NRS) & $3^{\ddagger}$ & $1.15^{\ddagger}$ \\
\hline
\end{tabular}

Values are mean \pm SD, number of patients (\%). NRS: numeric rating scale. *Distance from external occipital protuberance to injection site. ${ }^{\dagger}$ There were significant differences between Groups C and D (P $<0.05)$ with regard to partial and complete sensory change. ${ }^{\ddagger}$ There was a trend to significance difference between Groups $\mathrm{C}$ and $\mathrm{D}(\mathrm{P}=$ $0.05)$.

it has been reported on in the English literature. Complete blockade rate of doppler-guided GONB was significantly higher compared with the traditional technique, suggesting GONB can be more selectively and accurately accomplished using an ultrasonic doppler flowmeter. The traditional technique of GONB is easily performed [6], but the accuracy of blockade may be lower because of anatomical variations in GON's course, hair covering, and small size of the occipital artery [8]. As well, postblock complications (loss of consciousness, hematoma, bleeding, and dizziness) may occur using this method [10].

Greher et al. [11] reported success rates of ultrasound-guided GONB at the traditional site (superior nuchal line), and a newly described site more proximal ( $\mathrm{C} 2$, superficial to the obliquus capitis inferior muscle), on 10 cadavers were $100 \%$ and $80 \%$, respectively. The spread of dye $(0.1 \mathrm{ml}$ indocyanine dye) and coloration of nerve were evaluated by dissection. Ultrasound allowed real-time identification of the nerve, recognition variability in its course and needle position, and observed spreading of local anesthetics. However, in the living, practicability and sterility of this method because of probe size, ultrasonic jelly, and hair, need to be considered.

Naja et al. [12] evaluated the efficacy of nerve stimulatorguided occipital nerve block for postdural puncture headache. Complete pain relief was achieved in $68.4 \%$ of patients after 1 to 2 blocks. However, this method requires patient co-operation in reporting tingling sensation.

Many studies have reported occipital nerve block is an effective treatment for cervicogenic headache, cluster headache and occipital neuralgia. GONB are frequently performed either to diagnose or treat pain in occipital area [2,13-18]. GONB is effective for migraine and postdural puncture headache, but not for tension headache, post-traumatic headache, or hemicranias continua $[13,19,20]$. It has several advantages in treating headaches, including being a safe localized treatment and usually with no systemic effects. Onset is rapid, as short as 5 minutes [21], yet the effects of GONB can last for weeks [22].
Overall, GONB is easily performed, effective in headache and neuralgia, has few adverse effects, and can reduce symptomatic medication overuse. The ultrasonic doppler flowmeter probe used in this study was a hand-held type, small and light, and easily portable. Furthermore, the probe used an $8 \mathrm{MHz}$ beam for optimum sensitivity on superficial vessels. Because of its relatively small size, the practitioner can hold the probe in one hand, while injecting local anesthetics with the other. In summary, GONB can be easily performed without assistance.

This study showed that the success rate of complete blockade increased using an ultrasonic doppler flowmeter, with no complications. Furthermore, there was no significant difference pain reduction between the two groups.

When $3 \mathrm{ml}$ lidocaine was injected at the scalp, a large wheal formed. We believe the small amount of local anesthetics infiltrated around the occipital nerve even though the injection site was incorrect.

A major limitation of this study was that we did not record incidents of difficulty in palpation of the occipital artery pulsation. Therefore, we could not evaluate the efficacy of ultrasonic doppler flowmeter in these patients.

In conclusion, this study suggests that ultrasonic doppler flowmeter facilitates occipital nerve blocks, and reduces complications when using small amounts of local anesthetics.

\section{References}

1. Gawel MJ, Rothbart PJ. Occipital nerve block in the management of headache and cervical pain. Cephalalgia 1992; 12: 9-13.

2. Tobin J, Flitman S. Occipital nerve blocks: when and what to inject? Headache 2009; 49: 1521-33.

3. Ashkenazi A, Young WB. The effects of greater occipital nerve block and trigger point injection on brush allodynia and pain in migraine. Headache 2005; 45: 350-4.

4. Young WB, Marmura M, Ashkenazi A, Evans RW. Expert opinion: greater occipital nerve and other anesthetic injections for primary headache disorders. Headache 2008; 48: 1122-5.

5. Waldman S, Winnie AP. Greater and lesser occipital nerve block. In: Atlas of Interventional Pain Management. 2nd ed. Edited by Waldman S: Philadelphia, W.B. Sanders. 2003, pp 307-29.

6. Ward JB. Greater occipital nerve block. Semin Neurol 2003; 23: 5962.

7. Tubbs RS, Salter EG, Wellons JC, Blount JP, Oakes WJ. Landmarks for the identification of the cutaneous nerves of the occiput and nuchal regions. Clin Anat 2007; 20: 235-8.

8. Schmidt D, Adelmann G. The course of the occipital artery--an anatomical investigation for biopsy in suspected vasculitis. Eur J Med Res 2001; 6: 235-41.

9. Headache Classification Subcommittee of the International Headache Society. The international classification of headache disorders: 2nd edition. Cephalalgia 2004; 24 Suppl 1: 9-160.

10. Okuda Y, Matsumoto T, Shinohara M, Kitajima T, Kim P. Sudden unconsciousness during a lesser occipital nerve block in a patient 
with the occipital bone defect. Eur J Anaesthesiol 2001; 18: 829-32.

11. Greher M, Moriggl B, Curatolo M, Kirchmair L, Eichenberger U. Sonographic visualization and ultrasound-guided blockade of the greater occipital nerve: a comparison of two selective techniques confirmed by anatomical dissection. Br J Anaesth 2010; 104: 637-42.

12. Naja Z, Al-Tannir M, El-Rajab M, Ziade F, Baraka A. Nerve stimulator-guided occipital nerve blockade for postdural puncture headache. Pain Pract 2009; 9: 51-8.

13. Antonaci F, Pareja JA, Caminero AB, Sjaastad O. Chronic paroxysmal hemicrania and hemicrania continua: anaesthetic blockades of pericranial nerves. Funct Neurol 1997; 12: 11-5.

14. Tobin JA, Flitman SS. Occipital nerve blocks: effect of symptomatic medication: overuse and headache type on failure rate. Headache 2009; 49: 1479-85.

15. Anthony M. Headache and the greater occipital nerve. Clin Neurol Neurosurg 1992; 94: 297-301.

16. Naja ZM, El-Rajab M, Al-Tannir MA, Ziade FM, Tawfik OM. Occipital nerve blockade for cervicogenic headache: a double- blind randomized controlled clinical trial. Pain Pract 2006; 6: 89-95. 17. Inan N, Ceyhan A, Inan L, Kavaklioglu O, Alptekin A, Unal N. C2/ C3 nerve blocks and greater occipital nerve block in cervicogenic headache treatment. Funct Neurol 2001; 16: 239-43.

18. Afridi SK, Shields KG, Bhola R, Goadsby PJ. Greater occipital nerve injection in primary headache syndromes: prolonged effects from a single injection. Pain 2006; 122: 126-9.

19. Leinisch-Dahlke E, Jürgens T, Bogdahn U, Jakob W, May A. Greater occipital nerve block is ineffective in chronic tension type headache. Cephalalgia 2005; 25: 704-8.

20. Saadah HA, Taylor FB. Sustained headache syndrome associated with tender occipital nerve zones. Headache 1987; 27: 201-5.

21. Bovim G, Sand T. Cervicogenic headache, migraine without aura and tension-type headache: diagnostic blockade of greater occipital and supra-orbital nerves. Pain 1992; 51: 43-8.

22. Ashkenazi A, Levin M. Greater occipital nerve block for migraine and other headaches: is it useful? Curr Pain Headache Rep 2007; 11: 231-5. 